was only slight during the two days in which the bromide of potassium was continued. On the third day after admission, the patient complained of pain in the left wrist and stroulder, and right knee, which were found to be swollen and red; and after some trouble-caused by the difficalty the patient had in speaking; the result of the involverment of the tongue and muscles of articulation in the choreic disorder-we ascertained that the pain in the left wrist had existed for several days. He was obviously suffering at the same time, from both chorea and rheumatic polyarthritis. He was, therefore, given twenty grains of salicylate of soda every three hours, and the bromide of potassium was discontinued. Two days afterwards, the pain had disappeared from the wrist and shoulder; the temperature had fallen from $1008^{\circ}$ to $98.9^{\circ}$; and the choreic movements had conspicuously abated, being now present, in the continued and involuntary. form, only in the face, although, when voluntary movements were performed, they still ap. peared in the limbs and tongue. Four days after the commencement of the administration of salicylate of soda, the rheumatic polyarthritis had entirely disappeared, and the only remaining symptom of chorea was the jerking movement of the tongue when it was protruded and withdrawn. The very satisfactory result had, therefore, been obtained that, in four days, an acute rheumatic polyarthritis had been cured, and that, much beyond any anticipations I had entertained, at the same time, and under a treatment not usually followed in chorea, a specially severe example of this disease had apparently been cured.

The vicissitudes of our patient, however, had not yet come to an end. After continuing the administration of salicylate of soda for ten days, the appearance of its disagreeable effects in connection with the stomach and the sense of hearing, and the entire absence of any symptoms of rbeumatism, led to its being discontinued and arsenic substituted in its place. This change in treatment was most disastrous. On the third day following its adoption, the right wrist of the patient became swollen and red, the morning temperature rose to $100^{\circ}$ and the evening to IO2., and involuntary choreic movements appeared in both upper extremities. Ths salicylate was resumed, and on the second day thereafter the left wrist had returned to a normal condition, the temperature had fallen to $99^{\circ}$, and the chorea had almost disappeared. In a few days afterwards, the chorea entirely and finally disappeared. In order to complete the narrative of this case, and place you in possession of all the important facts that have occurred, I must add that on two subsequent occasions relapses recurred, which were restricted, however, to purely rheumatic manifestations, and to periods during which the patient was not beingitreated with salicylates; owing, to a great extent, to our desire to avoid the inconvenient toxic phenomena, to which he was peculiarly susceptible.

The relationship between chorea and rheumatism, and especially acute rheumatic polyarthritis, which is so forcibly illustrated in this case has long been recognised. First referred to by Bouteille and Berndt, it wass afterwards acknowledged by Copland, Scudamore, and Abercrombie, and more recently stated in the exact form of statistical enumeration by Hughes, Kirkes, Sée, Roger, and many other physicians. Its existence is now generally admitted, although occasionally it is regarded as a mere coincidence, the relationship being relegated even to the trivial bond which connects any depressing agent with the production of a disease. A case such as that which I have to-day described, undoubtedly affords very strong support in favour of a causal relationship. It affords support from two aspects of the case, from its time of occurrence, and from the results of the treatment. The former is so significant, in the first occurrence of the choreic disease as well as in its subsequent appearance during a relapse of the rheumatic fever, that it is impossible to overlook it. The lalter has, in addition to its equally clear significance, the further value that it constitutes a description of evidence, the quantity of which, so far as I know, is very limited. I can refer for evidence of probably a similar description only to the fact that some cases of chorea have been treated with success by Dr. Weir Mitchell and Dresch, with the same remedy as produced such striking results in my patient. The details of these cases I have not learned, and I therefore cannot tell you if they illustrate in so clear a manner the relationship between rheumatism and chorea by showing that the most certain remedies for the former disease with which we are acquainted - the several compounds of salicyl-may exert a like curative action upon chorea. It would be important to stil further test this point by treating a number of cases of chorea by salicyl compounds, and especially cases where the chorea does not present so close a relationship to the rheumatic affection as to suggest the possibility of its being a mere symptom of rheumatism This view is, indeed, one that has been already adopted. Its existence leads me to impress upon you the importance of avoiding any all-pervading opinion in regard to this disease. Nothing will appear more obvious, when the known facts in regard to chorea were considered, than that it is far from being the product of any single pathological condition. There is now much evidence to show that, at times, it is accompanied by a lesion of the corpus striatum, at others of the medulla oblongata, at others of the medulla spinalis, at others of some part of the peripheral nervous system, at others of ihe heart, and at others by no lesion that can be discovered in any of these situations.

I can scarcely hazard an opinion as to its production in the case I have braught before you. The embolic theory is here entirely inapplicable, because of the rapidity with which the disease disappeared on two separate occasions. The mere existence of cardiac disease, of rhepmatic origin, seems equally insufficient to afford an explanation. It existed before, the chorea, it has persisted after its disappearance; and, further, the chorea was, rapidly cured by salicylates, whereas salicylates do not directly affect the occurrence or the cnurse of cardiac disease in acute rheumatism. A reflex influence, originating from the inflamed joints, cannot account for the chorea, as it often appears in rheumatic patients, while no inflammation of joints is present; and, in our case, the joints, were on several occasions acutely inflamed, without a reappearance or an exacerbation of the chorea. Such a case would almost indicate that chorea may be a mere manifestation of acute rheumatism, in the same sense as the joint or heart affections, a mere complication of that disease, produced, it may be, a rheumatic inflammation of some portions of the central nervous system, whether true nerve-sub. stance or surrounding media.

\section{STRICTURE OF THE COLON.}

BY SIR JOSEPH FAYRER, M.D., K.C.S.I., F.R.S. Physician to the Secretary of State for India in Council.

THE following case of annular stricture of the colon is instructive. Its gradual formation and the attendant symptoms, which were the result of the slowly progressing obstruction, are of clinical interest, whilst the pathological changes are worthy of notice. The discovery of an epitkeliomatous growth (on the limb), which had been carefully concealed during life, suggested the possibility of malignancy in the bowel ; but, on careful examination, the stricture proved to be simply fibrous, and devoid of any trace of malignancy.

The previous health had been good; there had been neither diarrhœa, dysentery, nor ulceration to account for the stenosis. Latterly, the health had deteriorated, and there was emaciation, but the appetite had by no means failed. It was evident that an obstruction existed, and was increasing in the colon above the sigmoid flexure, but there was nothing to indicate its true nature. Thegradually increasing distension of the bowel showed that fæcal matter was accumulating in a large portion of the bowel, though beyond reach by the hand through the rectum.

In the hope that it might yield to treatment, and in the absence of urgent symptoms, operative interference by abdominal section was deferred. When at length permitted, though it gave some relief, it did no more. It is worthy of note that, beyond obstinate constipation, there was no very prominent symptom until just before the end ; there had been neither tenesmus, tormina, blood, nor mucus ; no vomiting, though occasional nausea; the urine had been freely secreted, and, though there was much inconvenience from distension, there had been little pain.

The appearance presented by the gut, when the opportunity for examining it arrived, was that as though a cord had been tightly tied round the bowel, just at the splenic flexure, constricting the calibre to an orifice through which a pin would pass with difficulty, this constriction consisting of a ring of dense fibrous tissue. For the rest, the bowel was healthy, showing no trace of former disease. The other viscera were also healthy. A certain amount of peritonitis had resulted from extravasation of fæcal matter where the over-distended bowel liad given way. Beyond this, and the existence of a large epitheliomatous growth. pendulous from the thigh; there was no evidence of disease; and careful microscopic examination failed to detect any sign of malignancy in the stricture itself.

The result of this case seems to show that earlier colotomy might have prolonged life. The indications for the operation were not sufficiently urgent at first to overcome the objections offered to it; but the importance of early surgical interference in similar cases is obviously suggested.

CASE. A widow lady, aged 64 , with no children, had resided in India for some years, where she had good health, excepting for occasional bilious attacks. She returned to England in 187 I, her general health unimpaired by residence in the Indian climate. During one or 
two winters after her neturn she suffered from bronchitis' but, in 1879 she had little or none. "In the stimmer of this year she underwent great anxiety land mental worry, owing to the dangerous, and ultimately fatal, illness of a near relation, and her own health began tn suffer. She had irregular' action of 'the bowets $;$ she always spoke' of bilious attacks. In July of that year, she went to Harrogate, and there appears to have been very much out of bealth, and to have lost ground, though tunder most careful and skifful treatment; the bowels were regulated, and her diet-a point in which she was apt to err-attended to.

She retuined to London early in November, but I did not see her until the 20 th of that month, and found her emaciated, and weaker than when I had last seen her. She was suffering from flatulent distension of the bowels, which were, however, acting daily or every other day. She expressed the greatest dislike to physic, especially if aperient, from which she said she suffered much lately. Some simple carminative, and a carefully regalated diet, were enjoined.

This 'state of 'things continued for some' weeks, with no great change ; the tympanites continuing to annoy her. Fomentations, carminatives, copious tepid enemata of sbap, oil, and water, occasionally of sweet-oil alone, were given, and generally for a time acted fairly well, sometimes freely. The tongure was generally clear; the pulse good ; there was no increase of temperature; the urine was copious, depositing lithates, but otherwise normal; the spirits were very good generally, and she very hopeful of recovery, saying that, but for the flatulence, she felt well. About a month before the end, the bowels began to be confined, and she had occasional fits of nausea, which were relieved by diluted hydrocyatic acid. At length, it became nscessary to have recourse to aperients, as the enemata failed to produce any effect. The tympanites increased; she was carefully dieted, and solid food prohibited. The bowels now became obstinately constipated, and she passed nothing for some days; withal, it was remarkable how little she seemed affected by it ; in some ways, she seemed better, and would get up, and even go out. The most careful examination could detect neither stricture in the rectum nor physical signs of any visceral disease.

It. was obvious that, aperients and enemata having failed, they strould not be repeated: She was brought under the influence of opium, when the tympanites was relieved, but there was no action of the bowels. The large intestine could be felt, though the abdominal wall distended with fæcal matter, Enemata again had no results; the obstruction was too high to be reached with the hand introduced into the bowel.

'The question of surgical operation now discussed, but it was not accepted.

Things went on much in the same way for a few days, when I was summoned and found her in great pain. Nothing had passed; the general condition was serious. An operation was proposed, and it was done without loss of time. The ascending colon was opened, a quantity of fecal matter escaped, and there was some relief. But symptoms of peritonitis set in rapidly, with collapse; and she sank in a few hours.

On examination of the body, it was found that the colon above the stricture, which was situated at the splenic flexure, was enormously distended with fæcal matter, that a portion of the intestines had given way, and that peritonitis had resulted from the extravasation. The bowel otherwise and the viscera generally were healthy. There was no cancerous infiltration of any organ, and the stricture was peculiar, presenting the appearance as of a cord tied round the gut. The passage was practically obliterated ; probably had been so for some days; it bad been gradually contracting for weeks, and, when complete occilusion of the passage occurred, the urgent symptoms had set in.

Beyond an epitheliomatous growth, pendulous from the inner part of the thigh, there was no disease. No glands were enlarged, no extension of malignant disease had taken place in any direction, and microscopic examination failed to detect any other than fibrous tissue in the stricture itself.

The origin of stricture of the bowel of this character is very obscure. I may add that $I$ saw another case about a year ago, of very much the same character, in a woman about 60 , where the origin was equally obscure.

Liability OF DENTISTs. - The liability of a dentist' for the consequences of his own carelessness, or want of skill, has been decided in the affirmative in the United States courts of law. A gentleman named Thomas J. Kelly brought an action, in New York, against a dentist for injuries. caused by a piece of tooth, which was extracted, but allowed by the operator to drop down the plaintiff's throat while he was under theiffluence of nitrous oxide. The piece slipped from the forceps, and for four weeks the plaintiff suffered great pain. Judgment was given for 500 dollars damages, and this has been apheld on appeal.

\section{OBSERVATIONS}

\author{
oN
}

THE PHYSIOLOGICAL AND THERAPEUTIC ACTION OF THE ELEMENT ARSENIC IN THE FORM OF ARSENITE AND ARSENIATE.

BY SYDNEY RINGER, M.D., F.R.C.P.,

Professor of Medicine in University College, and Physician to University College Hospital.

AND

HARRINGTON SAINSBURY, M.D., M.R.C.P.

Both oxides of the element arsenic-viz., arsenious and arsenic acidsare employed in medicine, either as such, or in combination with some base or other. In the British Pharmacopacia, the liquor potassæ arsenitis, the liquor arsenicalis, and the liquor sodæ arsenicatis, are given in practically equal doses. The solution strength of the former two is one part of arsenious acid in 120 parts of water; of the latter is one part of anhydrous arseniate of soda in 120 parts of water. Calculated out from their formulæ, it will be seen that the arseniate preparation contains a little over half as much metallic arsenic as either of the two arsenious acid preparations. This is practically recognising the arseniate as the more active preparation.

The present experiments were made in order to test this point, the inportance of which is apparent: Chemically considered, the arseniate is a stablex form of combination than the arsenite, the two salts standing to one another in the same relation as the phosphate and phosphite of the analagous element phosphorus, though the difference in degree of stability between these two latter combinations is much greater.

On the action of arsenious acid, there has been much work done; on the action of arsenic acid; but little. It is known generally that, qualitatively, arsenic acid acts similarly to arsenious acid; but, beyond this very general statement, little definite is discoverable. Of late, a series of papers have appeared (Archiv für experimentelle Pathologie und Pharmakologie) on the subject of the mode of action of the element arsenic in its oxygen compounds. In the first paper (Op. cit., Band xi, p. 213) the authors, Binz and Schulz, state, with reference to the comparative action of arsenious and arsenic acids, that some investigators have found that arsenic acid was slower in its action, whilst others have found it to be the more active preparation. They further state that, so far as their own task is concerned, which ol these two statements is the true one is unimportant. It is clear that no such statement as this could be made in the face of very definite experimental results, giving superiority of action to either of the two oxides of arsenic.

Some work, however, had been already done on this subject. Thus, in a paper by Wöhler and Frerichs (Annalen der Chemie und Pharmacie, Band lxv, 1848), "On the Changes'which Organic Bodies, in particular, suffer in their Passage into the Urine ;" two experiments with arsenic acid are quoted-one on a rabbit, one on a dog. From the results obtained, the authors concluded that arsenic acid was less poisonous than arsenious acid.

They further stated, as amongst the differences between the two oxides, that arsenic acid showed less local irritant and caustic action; that its effects appeared more slowly; and they suggested that these were probably, in part, due to a reduction to arsenious acid occurring in the alimentary canal; they thought that the marked injection of the large intestine which was found post mortem in the cases observed spoke in favour of this reduction.

With reference to this relative position of arsenious and arsenic acids, it is very natural that the analogous element, phosphorus, should have been looked to, in order to see if any particular relation existed between the corresponding oxides of this element. Of these, viz., the phosphorous and phosphoric acids, the latter, when its acidity is neutralised by a suitable base, e.g., soda, is very little, if at all, irritant ; phosphate of lime is, of course, a natural constituent of the organism, and, indeed, it is probably in the form of phosphate alone that the element phosphorus occurs in the tissues.

As to the action of phosphorous acid, but little work has been done; it is not employed in therapeutics, nor mentioned in text-books on toxicology. In the above-mentioned paper (Op. cit., p. 347), however, Wöhler and Frerichs quote some experiments, three in number, with phosphorous acid; the doses used were from 0.5 gramme to I gramme 